\title{
RANCANG BANGUN SISTEM PENGEPRESAN DENGAN PENGGERAK PNEUMATIK PADA MESIN PRESS DAN POTONG UNTUK PEMBUATAN KANTONG PLASTIK UKURAN 400 X 550 MM
}

\author{
Rudy Febri Indriyanto \\ Fakultas Teknik, Program Studi Teknik Mesin \\ Universitas Muria Kudus \\ Email: rudyfbr@gmail.com \\ Masruki Kabib \\ Fakultas Teknik, Program Studi Teknik Mesin \\ Universitas Muria Kudus \\ Email: masruki.kabib@umk.ac.id

\section{Rochmad Winarso} \\ Fakultas Teknik, Program Studi Teknik Mesin \\ Universitas Muria Kudus \\ Email: rochmad.winarso@umk.ac.id
}

\begin{abstract}
ABSTRAK
Pengepresan kantong plastik selama ini masih banyak menggunakan sistem dengan penggerak manual atau mekanik yang mengakibatkan hasil pengepresan dari plastik kurang sempurna, karena tekanan yang diberikan satu dengan yang lain berbeda. Tujuan dari penelitian ini adalah merancang dan membuat press kantong plastik 400 × $550 \mathrm{~mm}$ dengan penggerak sistem pneumatik. Metode rancang bangun yang digunakan dalam pembuatan mesin ini meliputi kajian pustaka, analisa kebutuhan pengepresan plastik, konsep desain press pneumatik, perhitungan kapasitas, dan analisa simulasi pengepresan. Dalam tahap pembuatannya meliputi beberapa proses yaitu gambar kerja, pemotongan bahan, perakitan sistem pengepresan, dan uji coba mesin press untuk mengetahi hasil pembuatan mesin. Hasil rancang bangun mesin potong dan press plastik ukuran 400 x $550 \mathrm{~mm}$ ini adalah kapasitas pengepresan 500 press/jam , pemanas menggunakan daya 500 watt dengan 2 Stripe Heater masing-masing dengan daya 250 watt, untuk penggunaan silinder pnumatik menggunakan silinder dengan diameter $20 \mathrm{~mm}$ dengan batang torak berdiameter $8 \mathrm{~mm}$.
\end{abstract}

Kata kunci: pengepresan; sistem pneumatic; kantong plastik.

\begin{abstract}
The plastic bag presses have so far used many manual or mechanical drive systems which have resulted in imperfect plastic pressing, due to the different pressure given to one another. The purpose of this study is to design and make press $400 \times 550 \mathrm{~mm}$ plastic bags with pneumatic system driven.The design method used in the manufacture of this machine includes literature review, plastic pressing needs analysis, pneumatic press design concept, capacity calculation, and pressing simulation analysis. In the manufacturing phase, it includes several processes, namely working drawings, cutting material, pressing system assembly, and press machine testing to find out the results of machine manufacture.The design of the $400 \times 550 \mathrm{~mm}$ plastic cutting and press machine is 500 press / hour pressing capacity, the heater uses 500 watts of power with 2 Stripe Heaters each with 250 watts of power, for the use of a pneumatic cylinder using a cylinder with a diameter of $20 \mathrm{~mm}$ with piston rod $8 \mathrm{~mm}$ in diameter.
\end{abstract}

Keywords: pressing; pneumatic systems; plastic bags.

\section{PENDAHULUAN}

Proses pembuatan kantong plastik banyak dilakukan oleh industri kecil. Permasalahan yang terjadi adalah diperlukan pengepresan kantong plastik dengan sistem kontinyu dan kapasitas yang lebih besar. Proses pembuatan yang dilakukan industri kecil sebagian besar masih menggunakan cara cara manual atau 
mekanik. Sistem pengepresan plastik ini dianggap kurang optimal dan kemampuan kapasitasnya relatif kecil [1].

Kantong Plastik merupakan bahan yang banyak dibutuhkan untuk pengemasan produk. Penggunaan kantong plastik juga harus dibatasi, karena merupakan bahan yang sulit diurai oleh mikro organisme. Bahan kantong plastik dapat menggunakan alternatif pati ubi jalar [2].

Sistem penggerak untuk pengepresan plastik dapat menggunakan sistem pneumatik. Sistem pneumatik merupakan sistem penggerqk yang memanfaatkan udara bertekanan. Sistem Gerak yang bisa dilakukan oleh aktuator pneumatik adalah gaya dorong dan gaya tarik. Sistem penggerak pneumatic dapat bekerja secara kontinyu [3]. Sistem gerak aktuator pneumatik pada mesin pres dapat di pasang secara vertikal dan horizontal [4]. Aktuator bergerak dengan membawa beban massa komponen pres dan menghasilkan gaya pengerpresan. Gaya yang dihasilkan aktuator pneumatik berbeda dengan sistem hidrolik untuk proses pengepresan [5].

Sistem pengepres plastik menggunakan elemen pemanas dengan sumber energi dari listrik. Bahan yang digunakan untuk elemen pemanas biasanya adalah kawat nikelin yang dilapisi bahan isolator. Pada kedua ujung kawat nikelin dialiri arus listrik, sehingga akan menghasilkan panas yang dapat digunakan untuk pengepresan plastik [6].

Kantong plastik banyak dibutuhkan untuk bahan pengemas berbagai produk dan makanan. Untuk menghasilkan kantong plastik di butuhkan alat potong dan press yang dapat bekerja secara kontinyu dengan kualitas yang baik. Untuk memenuhi kebutuhan alat potong dan pres kantong plastik dapat dikembangkan dengan sistem penggerak pneumatic.

Penelitian ini bertujuan untuk merancang dan membuat press kantong plastik ukuran 400 x $550 \mathrm{~mm}$ dengan penggerak sistem pneumatik. Sistem pengepresan menggunakan penggerak aktuator pneumatik. Bidang pengepresan dari bahan lempengan yang berfungsi sebagai pengepres kantong plastik dengan ukuran $550 \mathrm{~mm}$. Mekanisme proses dapat mengepres plastik pada setiap panjang $550 \mathrm{~mm}$, dengan penyesuaian putaran roll yang dibutuhkan untuk mendapatkan panjang plastik $550 \mathrm{~mm}$. Pengendalian gerak menggunakan sistem kontol yang dapat mengatur gerak sebuah motor stepper, ketika putaran motor stepper yang telah diinginkan telah tercapai sistem kontrol harus memberikan sinyal kepada motor stepper untuk berhenti dan sistem kontrol melanjutkan untuk memerintah katup selenoid dan selenoid elektrik untuk bekerja, proses tersebut dilakukan secara berulang-ulang pada sistem mesin pres kantong plastik ini.

\section{METODOLOGI PENELITIAN}

Untuk melakukan perancangan dan pembuatan mesin press kantong plastik ada beberapa langkah yang harus dilakukan yaitu :

\subsection{Proses Perancangan Sistem Pengepresan Kantong Plastik}

Perancangan dilakukan terlebih dahulu sesuai dengan langkah - langkah proses desain. Analisa kebutuhan pengepresan plastik yang dilakukan dalam proses analisa kebutuhan meliputi aspek manufaktur, aspek produksi, aspek ergonomis, dan aspek keselamatan kerja. Konsep desain sistem pengepresan memiliki dua macam konsep yang akan dibandingkan untuk melihat perbedaanya antara konsep pertama dan konsep kedua yang memiliki kriteria berbeda-beda. Perhitungan perencanaan sistem pengepresan kantong plastik yang terdiri dari pemomotongan material, perhitungan elemen pemanas, Batang pengarah, perhitungan sistem pnumatik, dan perhitungan rangka.

\subsection{Proses Pembuatan Sistem Pemotong Kantong Plastik}

Dalam proses manufaktur sistem pengepresan kantong plastik dilakukan pemahaman gambar desain dan mempelajari proses kinerja mesin. Berikut adalah beberapa proses pembuatan yag dilakukan yaitu: 1) Pembuatan rangka sistem pengepresan kantong plastik harus terlebih dahulu mempersiapkan alat dan bahan yang digunakan serta memahami gambar kerja yang digunakan. Beberapa langkah - langkah yang dilakukan dalam pembuatan yaitu pengukuran, menitik benda kerja, memotong, mengebor, dan mengelas. 2) Pembuatan tempat elemen pemanas dan tempat silinder pnumatik memiliki beberapa hal yang harus dilakukan dalam pembuatan sistem pengepresan seperti memahami gambar kerja yang harus dilakukan, pengukuran pemotongan, pengelasan dan pengeboran dan yang terakhir merangkai sistem pneumatik. 


\section{HASIL DAN PEMBAHASAN}

\subsection{Pemilihan Konsep Desain}

Dalam pemilihan konsep desain meliputi beberapa aspek yang dapat dijelaskan pada Gambar 1.

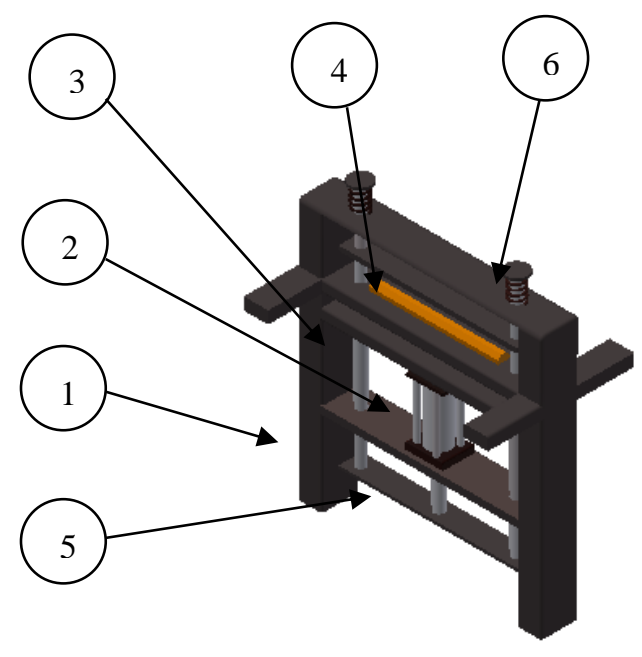

a.

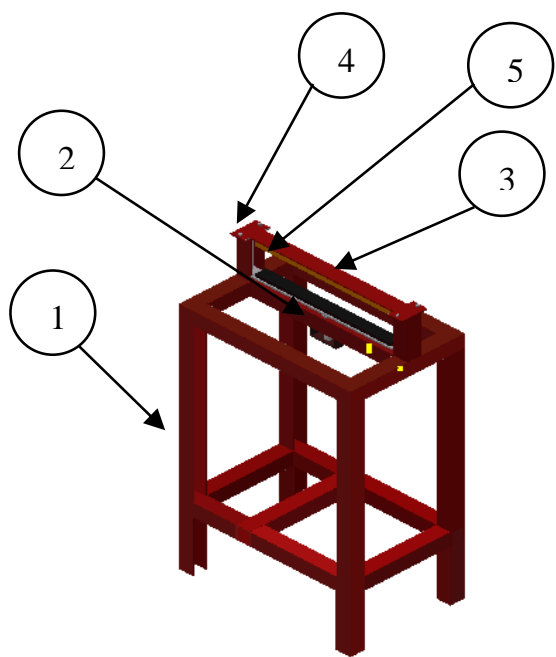

b.

\section{Gambar 1. (A)Konsep Desain Pertama Dan (B) Konsep Desain Kedua}

Pada gambar 1 (a) konsep pertama dengan komponen: 1) rangka, 2) aktuator, 3) pemanas, 4) as penghubung, 5) plat penghubung, 6) pegas. Pada gambar 1 (b) konsep kedua dengan komponen: 1) rangka, 2) aktuator, 3) pemanas, 4) poros penghubung, 5) plat penghubung.

Pemilihan konsep desain yang memenuhi persyaratan sistem pengepresan kantong plastik adalah konsep yang kedua atau konsep (b), dengan alasan desain pengepresan lebih praktis tidak membutuhkan komponen atau material yang banyak, biaya pembuatan yang lebih murah dan hasil pengepresan akan lebih baik dibandingkan konsep pertama.

Mekanisme kerja dari sistem pengepresan menggunakan sistem pnumatik ini adalah mesin kantong plastik ini menggunakan motor steper untuk menggerakkan roll dengan kapasitas potong 500 press/ jam, pengepresan akan digerakkan oleh penggerak silinder pnumatik, pada saat katup selenoid mendapat sinyal dari sistem kontrol katup akan membuka dan udara akan mengalir sehingga piston bergerak positif atau menekan plastik ke pemanas sehingga pengepresan plastik dapat berlangsung, setelah proses pengepresan plastik akan diteruskan roll menuju pemotongan dan akan diteruskan ke proses perhitungan 100 pcs plastik dapat bergeser untuk memenuhui kebutuhan pengepresan 500 press/ jam.

\subsection{Perhitungan Perancangan Yang Digunakan}

Perhitungan dalam perancangan spesifikasi didasarkan pada beberapa rumus sebagai berikut :

\subsubsection{Perhitungan elemen Pemanas}

Perhitungan dalam perancangan pemanas menggunakan persamaan 1 [7].

$$
\mathrm{P}=\frac{\mathrm{V}^{2}}{\mathrm{R}}
$$

Dimana $\mathrm{P}$ adalah daya heater, $\mathrm{V}$ adalah tegangan, dan $\mathrm{R}$ adalah hambatan

\subsubsection{Perhitungan Gaya pengepresan}

Perhitungan gaya pengepresan dapat dicari dengan menggunakan persamaan 2 [1]

$F=P . A$ 
Dimana $\mathrm{F}$ adalah gaya pengepresan $(\mathrm{N}), \mathrm{P}$ adalah tekanan $\left(\mathrm{N} / \mathrm{m}^{2}\right)$, dan A adalah luasan permukaan yang akan di press $\left(\mathrm{m}^{2}\right)$

\subsubsection{Perhitungan aktuator}

Perhitungan perencanaan aktuator pneumatik didasarkan pada persamaan 3 dan 4 [1]:

Diameter silinder

$$
\mathrm{D}^{2}=\frac{\mathrm{F}}{\frac{\pi}{4} \cdot \mathrm{p} \cdot \mu}
$$

Dimana D adalah diameter silinder, $\mathrm{F}$ adalah gaya pengepresan, $\mathrm{P}$ adalah tekanan, $\mu$ adalah koefisien gesek.

Diameter batang torak

$$
\mathrm{d}^{4}=\frac{54 \cdot L^{2} \cdot F \cdot S}{\pi \cdot \mathrm{E}}
$$

Dimana d adalah diameter batang torak, L adalah jarak gerakan, $\mathrm{F}$ adalah gaya pengepresan, $\mathrm{s}$ adalah faktor keamanan, E adalah modulus elastisitas. Dari perhitungan tersebut didapatkan hasil pada tabel 1.

Tabel 1. Komponen press

\begin{tabular}{lll}
\hline Bagian & Jenis komponen & Hasil \\
\hline Komponen Press & Pemanas & Daya $=500 \mathrm{watt}$ \\
& Pneumatik & Diameter torak $=20 \mathrm{~mm}$ \\
& & Diameter batang torak $=8 \mathrm{~mm}$ \\
& Tekanan kerja $=3,6 \mathrm{bar}$ \\
& Debit $=1,4$ liter $/$ menit \\
\hline
\end{tabular}

\subsection{Analisa Simulasi Aliran Pneumatic}

Pada proses simulasi ini menggunakan bantuan software pneumatik, program ini mampu membuat permodelan sistem pneumatik. Pada proses ini rangkaian sistem pneumatik digambar dan diberi spesifikasi sesuai dengan yang direncanakan dalam perhitungan sebelumnya, adapun pada proses ini yang dimasukkan kedalam spesifikasi adalah sebagai berikut : Kompresor penampung udara adalah 6 bar, Filter udara dan saringan udara sebesar 3,6 bar, katup selenoid 5/2 dengan tegangan 24 volt dan diberi ground, nozzle sebesar 1,4 liter/menit dan gaya tekan silinder sebesar 96,49 N.
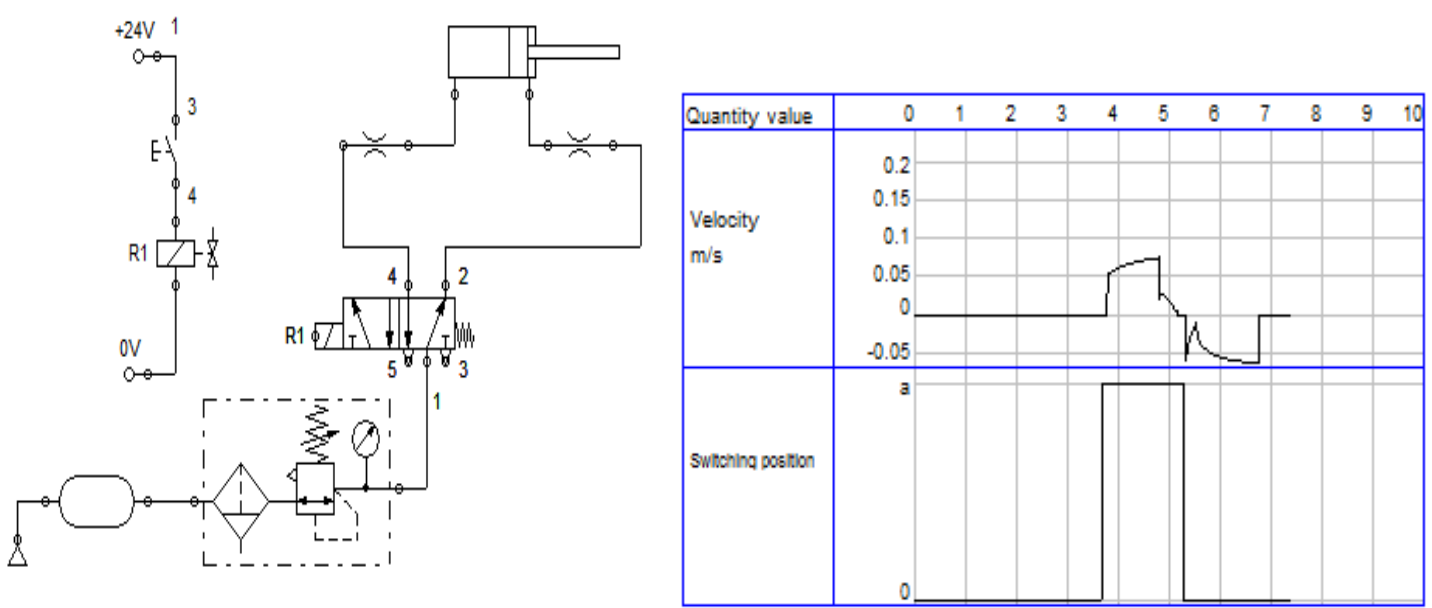

Gambar 2. Rangkaian dan Hasil Simulasi 
Pada simulasi gambar 2 adalah rangkaian sistem pneumatic untuk mesin pres dan hasil simulasi, hasil pada pengujian ini piston dengan beban 96,49 $\mathrm{N}$ mampu digerakkan dengan sistem pneumatik yang direncanakan sebelumnya, dan dihasilkan kecepatan sebesar 0,075 m/detik.

\subsection{Proses Pembuatan}

\subsubsection{Pembuatan Dudukan Heater}

Dudukan heater digunakan untuk tempat pemanas yang berfungsi sebagai alat untuk pengepresan kantong plastik, bentuk dan ukuran ditunjukkan pada gambar 3.

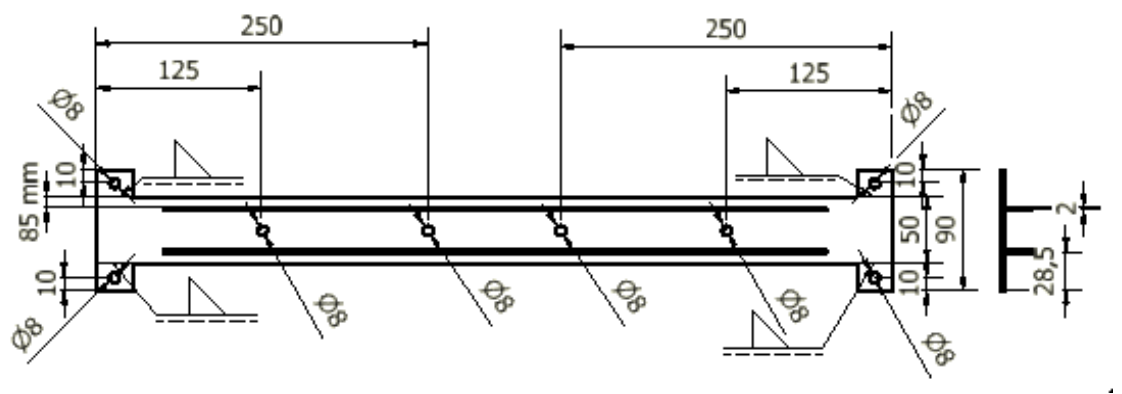

Gambar 3. Pembuatan Dudukan Heater

a. Pengeboran

Langkah pengawalan dapat dicari dengan menggunakan persamaan 5 [8].

$l v=\tan 59^{0} \frac{1}{2} \mathrm{~d}$

Dimana lv adalah langkah pengawalan, d adalah diameter mata bor. Langkah pengakhiran dapat dihitung menggunakan persamaan 6 [8].

$\ln =\tan 59^{0} \frac{1}{2} \mathrm{~d}$

Dimana In adalah langkah pengakhiran, d adalah diameter mata bor. Kecepatan pengeboran dihitung dengan menggunakan persamaan 7 [8].

$$
\mathrm{n}=\frac{\mathrm{v} .1000}{\pi \cdot \mathrm{d}}
$$

Dimana $\mathrm{n}$ adalah kecepatan pengeboran, $\mathrm{v}$ adalah kecepatan potong, $\mathrm{d}$ adalah diameter mata bor. Laju pemakanan pengeboran dapat dihitung dengan menggunakan persamaan 8 [8].

$$
f=0,084 \cdot \sqrt[3]{d}
$$

Dimana f adalah laju, d adalah diameter mata bor. Kecepatan makan dapat dihitung dengan menggunakan persamaan 9 [8].

$$
\mathrm{v}_{\mathrm{f}}=\mathrm{f} . \mathrm{n}
$$

Dimana Vf adalah kecepatan makan, f adalah laju, $\mathrm{n}$ adalah Kecepatan pengeboran. Panjang pengeboran dapat dihitung dengan menggunakan persamaan 10 [8].

$$
\left(1_{t}\right)=\left(1_{v}\right)+\left(1_{w}\right)+\left(1_{n}\right)
$$

Dimana lt adalah panjang pengeboran, lv adalah langkah pengawalan, lw adalah panjang pemotongan benda kerja, lv adalah langkah pengakhiran. 
Waktu pengeboran dapat dihitung dengan menggunakan persamaan 11 [8].

$$
t_{c}=\frac{l t}{v f}
$$

Dimana tc adalah waktu pengeboran lt panjang pengeboran, vf adalah Kecepatan makan.

b. Penyambungan Las

Panjang luasan las dihitung dengan persamaan 12 [9].

$\mathrm{A}=\mathrm{a} .1$

A adalah panjang luasan las, a adalah tebal plat, 1 adalah panjang sambungan las. Waktu Pengelasan dihung dengan persamaan 13 [9]

$\mathrm{t}=\frac{\text { tot panjang kampuh }}{\text { panjang per } 1 \text { menit }}$

Panas dapat dihitung dengan persamaan 14 [10].

$\mathrm{J}=\frac{60 \cdot \mathrm{I} \cdot \mathrm{E}}{\mathrm{V}}$

Dimana $\mathbf{J}$ adalah panas pengelasan, I adalah arus listrik, E adalah Tegangan busur, V laju pengelasan. Dari perhitungan diatas didapatkan waktu pengeboran dan pengelasan yang tertera pada tabel 2.

Tabel 2. Hasil waktu pembuatan dudukan heater

\begin{tabular}{clc}
\hline Jenis permesinan & \multicolumn{1}{c}{ Bagian } & Hasil \\
\hline Pengeboran & $\begin{array}{l}\text { Pengeboran dengan } \varnothing 8 \mathrm{~mm} \\
\text { sebanyak 8 lubang. }\end{array}$ & 41,28 detik \\
Pengelasan & $\begin{array}{l}\text { Pengelasan dengan panjang 27 mm } \\
\text { sebanyak 4 kali pengelasan. }\end{array}$ & 2,88 menit \\
Pengelasan & $\begin{array}{l}\text { Pengelasan dengan panjang 20 mm } \\
\text { sebanyak 8 kali pengelasan. }\end{array}$ & 2,13 menit \\
\hline
\end{tabular}

Dari proses pengeboraan dengan $\emptyset 8 \mathrm{~mm}$ terdapat hasil sebagai berikut : langkah pengawalan sebesar 6,65 mm, langkah pengakhiran sebesar $6,65 \mathrm{~mm}$, kecepatan pengeboran $1194 \mathrm{rpm}$, laju 0,168 mm/put, kecepatan makan $200 \mathrm{~mm} /$ menit, Panjang pengeboran 17,30 mm. Pada proses pengelasan dengan panjang $27 \mathrm{~mm}$ untuk pengelasan sebanyak 4 kali didapatkan data hasil sebagai berikut : panjang luasan yang dilas $432 \mathrm{~mm}^{2}$, menggunakan 2,88 elektroda, panas yang dihasilkan $88000 \mathrm{Joule} / \mathrm{cm}$. Proses pengelasan dengan panjang $20 \mathrm{~mm}$ untuk pengelasan sebanyak 8 kali didapatkan hasil sebagai berikut : panjang luasan yang dilas $320 \mathrm{~mm}^{2}$, menggunakan 2,13 elektroda, panas yang dihasilkan 70400 Joule/ cm.

\subsubsection{Pembuatan Penghantar Panas Kuningan}
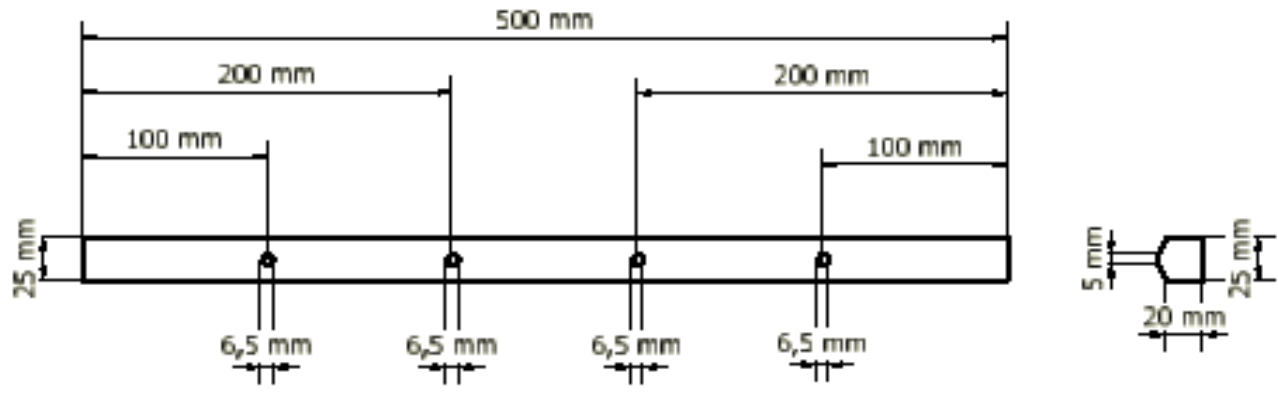

Gambar 4. Pembuatan Penghantar Panas Kuningan 
Pembuatan lubang penghantar heater sebagaimana gambar 6 dengan waktu pengeboran yang tertera pada tabel 3 .

Tabel 3. Hasil waktu pembuatan penghantar panas kuningan

\begin{tabular}{clc}
\hline Jenis permesinan & \multicolumn{1}{c}{ Bagian } & Hasil \\
\hline Pengeboran & $\begin{array}{l}\text { Pengeboran dengan } \emptyset \quad 6,5 \mathrm{~mm} \\
\text { sebanyak 4 lubang }\end{array}$ & 41,28 detik \\
\hline
\end{tabular}

Proses pengeboraan dengan $\emptyset 6,5 \mathrm{~mm}$ terdapat hasil sebagai berikut : langkah pengawalan sebesar $6,96 \mathrm{~mm}$, langkah pengakhiran sebesar $6,96 \mathrm{~mm}$, kecepatan pengeboran $1469 \mathrm{rpm}$, laju 0,156 mm/put, kecepatan makan $230 \mathrm{~mm} /$ menit, Panjang pengeboran 23,94 mm.

\subsubsection{Pembuatan Kerangka}

Proses pembuatan rangka mengacu pada gambar desain rangka seperti yang ditunjukkan pada gambar 5.
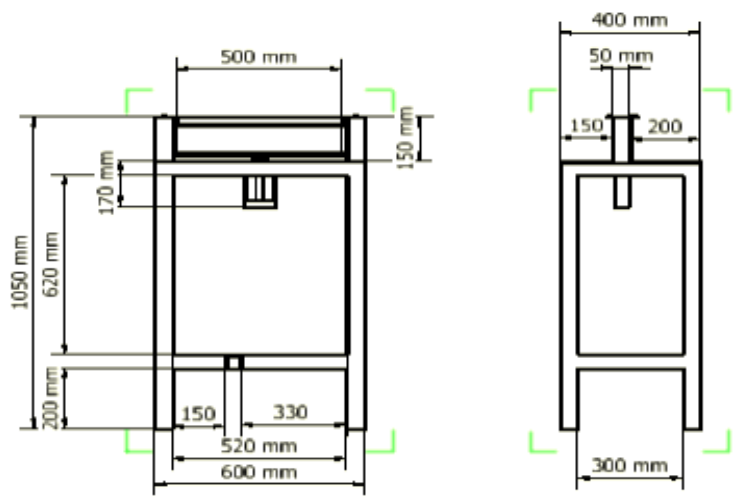

\section{Gambar 5. Pembuatan Kerangka} tabel 4.

Dari perhitungan pembuatan rangka didapatkan waktu pengeboran dan pengelasan yang tertera pada

Tabel 4. Hasil waktu pembuatan kerangka

\begin{tabular}{clc}
\hline Jenis permesinan & \multicolumn{1}{c}{ Bagian } & Hasil \\
\hline Pengeboran & $\begin{array}{l}\text { Pengeboran dengan } \emptyset 8 \mathrm{~mm} \\
\text { sebanyak 2 lubang. }\end{array}$ & 4,8 detik \\
Pengeboran & $\begin{array}{l}\text { Pengeboran dengan } \emptyset 22 \mathrm{~mm} \\
\text { sebanyak 1 lubang. }\end{array}$ & 4,52 detik \\
Pengelasan & $\begin{array}{l}\text { Pengelasan dengan panjang } 90 \mathrm{~mm} \\
\text { sebanyak 20 kali pengelasan. }\end{array}$ & 24 menit \\
\hline
\end{tabular}

Dari proses pengeboraan dengan $\emptyset 8 \mathrm{~mm}$ terdapat hasil sebagai berikut : langkah pengawalan sebesar $6,65 \mathrm{~mm}$, langkah pengakhiran sebesar $6,65 \mathrm{~mm}$, kecepatan pengeboran $1194 \mathrm{rpm}$, laju 0,168 mm/put, kecepatan makan $200 \mathrm{~mm} / \mathrm{menit}$, Panjang pengeboran 15,30 mm. Proses pengeboraan dengan $\varnothing 22 \mathrm{~mm}$ terdapat hasil sebagai berikut : langkah pengawalan sebesar 18,304 mm, langkah pengakhiran sebesar $18,304 \mathrm{~mm}$, kecepatan pengeboran $434 \mathrm{rpm}$, laju 0,235 mm/put, kecepatan makan $512 \mathrm{~mm} / \mathrm{menit}$, Panjang pengeboran $38 \mathrm{~mm}$. Proses pengelasan dengan panjang $90 \mathrm{~mm}$ untuk pengelasan sebanyak 20 kali didapatkan hasil sebagai berikut : panjang luasan yang dilas $3600 \mathrm{~mm}^{2}$, menggunakan 24 batang elektroda, panas yang dihasilkan 70400 Joule/ $\mathrm{cm}$.

\subsubsection{Pembuatan Cetakan}

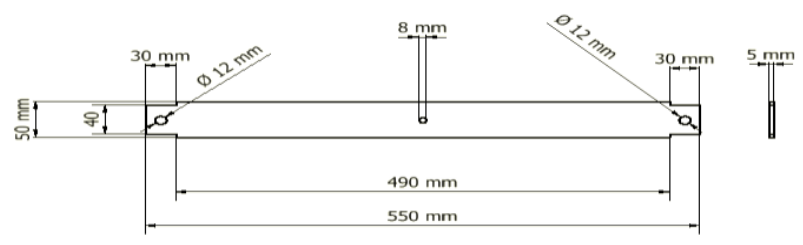

Gambar 6. Pembuatan Cetakan 
Gambar kerja untuk Pembuatan cetakan sebagaimana ditunjukkan gambar 6 dan waktu pengeboran sebagaimana ditunjukkan tabel 5.

Tabel 5. Hasil waktu pembuatan cetakan

\begin{tabular}{clc}
\hline Jenis permesinan & \multicolumn{1}{c}{ Bagian } & Hasil \\
\hline Pengeboran & $\begin{array}{l}\text { Pengeboran dengan } \emptyset 8 \mathrm{~mm} \\
\text { sebanyak 1 lubang. }\end{array}$ & 4,57 detik \\
Pengeboran & $\begin{array}{l}\text { Pengeboran dengan } \emptyset 12 \mathrm{~mm} \\
\text { sebanyak 2 lubang. }\end{array}$ & 14,28 detik \\
\hline
\end{tabular}

Dari proses pengeboraan dengan $\emptyset 8 \mathrm{~mm}$ didapatkan hasil sebagai berikut : langkah pengawalan sebesar 6,65 mm, langkah pengakhiran sebesar 6,65 mm, kecepatan pengeboran $1194 \mathrm{rpm}$, laju 0,168 $\mathrm{mm}$ /put, kecepatan makan $200 \mathrm{~mm} /$ menit, Panjang pengeboran 18,32 mm. Proses pengeboraan dengan $\emptyset$ $12 \mathrm{~mm}$ terdapat hasil sebagai berikut : langkah pengawalan sebesar $6,65 \mathrm{~mm}$, langkah pengakhiran sebesar 6,65 mm, kecepatan pengeboran $796 \mathrm{rpm}$, laju 0,192 mm/put, kecepatan makan $153 \mathrm{~mm} / \mathrm{menit}$, Panjang pengeboran $18,31 \mathrm{~mm}$.

\section{KESIMPULAN}

Dari hasil perhitungan perancaangan mesin press kantong plastik ukuran 400 x $550 \mathrm{~mm}$ dengan sistem pneumatik dapat ditarik kesimpulan sebagai berikut :Daya heater 500 watt, menggunakan 2 batang heater dengan masing- masing stripe 250 watt, Gaya penekanan sebesar 96,49 $\mathrm{N}$ dan gaya tarik silinder sebesar $80,71 \mathrm{~N}$, Penggunaan silinder pneumatik menggunakan silinder dengan diameter $20 \mathrm{~mm}$ dan untuk batang torak berdiameter $8 \mathrm{~mm}$., Kapasitas udara yang harus dialirkan kompresor sebesar 1,4 1/menit, Total waktu pengelasan dan pengeboran 31 menit.

\section{DAFTAR PUSTAKA}

[1] B. Lutfi and F. T. P. H, "Mesin pengepres plastik dengan sistem penggerak pneumatik," Surabaya, 2014.

[2] S. Aripin, B. Saing, and E. Kustiyah, "Studi Pembuatan Bahan Alternatif Plastik Biodegradable Dari Pati Ubi Jalar Dengan Plasticizer Gliserol Dengan Metode Melt Inter calation,” J. Tek. Mesin, vol. 06, pp. 18-23, 2017.

[3] N. Hudallah, "Rancang Bangun Sistem Pnumatis Untuk Pengembangan Modul-Modul Gerak Otomatis Sebagai Media Pembelajaran,” Tek. Elektro, vol. 2, no. 1, pp. 8-22, 2010.

[4] G. P. Sonawane, G. Shashikant Udgirkar, S. V. Shirsath, M. S. Deshpande, and B. E. Students, "Design, Analysis and Manufacturing of Hydro-pneumatic Press Machine," ISSN || Int. J. Comput. Eng. Res., vol. 04, no. 11, pp. 2250-3005, 2014.

[5] M. Kabib, I. M. L. Batan, B. Pramujati, and A. S. Pramono, "Analisa Pemodelan dan Simulasi Gerak Aktuator Punch pada Mesin Pres untuk proses Deep Drawing,” no. Snttm Xiv, pp. 7-8, 2015.

[6] S. D. Ariffudin and D. Wulandari, "Perancangan Sistem Pemanas Pada Rancang Bangun Mesin Pengaduk Bahan Baku Sabun Mandi Cair Satriya Dwi Ariffudin,” JRM, vol. 01, no. 02, pp. 52-57, 2014.

[7] S. Huda, M. Kabib, and R. Winarso, "Desain Automatic Line Plastic Packing Of Cake Berbasis Mikrokontroler Atmega 328,” Pros. Snatif Ke-4, pp. 577-584, 2017.

[8] T. Rochim, Proses permesinan. Jakarta: Erlangga, 1993.

[9] wiryo sumarto Hartono and T. Okomura, Teknologi Pengelasan. Jakarta: Pradnya Paramita, 2000.

[10] Terheijden, Alat-alat perkakas 3. Bandung: Bina Cipta, 1971. 